Jurnal Ilmu Keperawatan : Journal of Nursing Science 2020, Vol. 8, No. 1, 35-42

www.jik.ub.ac.id

Doi 10.21776/ub.jik.2020.008.01.1

P-ISSN: 2088-6012 E-ISSN: 2598-8492

Review article

\title{
EFFECTIVENESS OF MINDFULNESS-BASED COGNITIVE THERAPY (MBCT) TOWARDS DEPRESSION
}

Maria Julieta Esperanca Naibili", Iman Permana²

Afiliasi

1. Student Master of Nursing, Post-graduate faculty, Muhammadiyah University of Yogyakarta,

2. Lecturer Medical Study Program, Faculty of Medicine and Health Sciences, Muhammadiyah University of Yogyakarta

Dikirim 26 Februari 2019

Direvisi 14 Agustus 2019

Diterima 13 Januari

Dipublikasi 30 Juni 2020

*Korespondensi

Email :

julietanaibili@gmail.com

\begin{abstract}
Depression is a common mental disorder that is leading cause of disability in the world by 2020 and a major contributor to overall global disease burden. Globally, more than 300 million people of all ages suffer from depression and more women. Depression can affect aspects of life including psychological, physical, and social. MBCT teaches patients through the mind, feelings, and body sensations to see an event temporarily without treating the event as an accurate reality. The aim of the study was to providing information about the effectiveness of MBCT towards depression. The relevant health databases include PubMed, Science Direct, Garuda, Emerald Insight, EBSCO, Google Scholar, Google Search, ProQuest, searched using a combination of keywords: 'mindfulness-based cognitive therapy' and 'depression' and 'randomized controlled trial'. The result of electronic search of the database identified 633 articles relating to MBCT. Furthermore, checking for duplicate and published articles, 620 criteria-filled studies, 128 full texts of 128 articles, 118 did not meet inclusion criteria for reasons not to investigate MBCT ( $n=61$ ), participants were not depressed/depressive disorder ( $n$ $=39)$ not a randomized controlled trial design $(n=14)$ published in letters, comments, editorials $(n=4)$. Then, the full text of the manuscripts included in the review amounted to 11 articles. In conclusion MBCT is an effective, acceptable, feasible, accessible, applicable form of mental health psychotherapy that aims to reduce symptoms of depression, anxiety, emotional distress and improve quality of life, improve social well-being, and improve psychological well-being. It is recommended that the MBCT be used for treating and recovered depressed patients.
\end{abstract}

Keywords: Depression, Mindfulness-Based Cognitive Therapy, Randomized Controlled Trial

Sitasi jurnal :

Naibili MJE \& Permana I. 2020. Effectiveness Of Mindfulness-Based Cognitive Therapy (MBCT) Towards Depression. Jurnal Ilmu Keperawatan Volume 8(1): 35-42. Doi 10.21776/ub.jik.2020.008.01.6 


\section{INTRODUCTION}

Good mental health is closely related to one's mental or psychological well-being. One common mental disorder that causes a person to experience mood disorders, affects the ability to think, reduces motivation in action, affects body functions, feels crashed and abandoned, and feels unable to do anything called depression (Segal, et al., 2012).

Depression is the number one cause of disability in developed countries and is projected to be the second leading cause of disability in the world by 2020 and a major contributor to overall global disease burden (Murray, 1996 cit Eisendrath, et al., 2014; WHO, 2018). Based on WHO (2018). Globally, more than 300 million people of all ages suffer from depression. More women are depressed than men. The most dangerous thing is that depression can trigger an individual to commit suicide. About 800,000 people die from suicide each year (WHO, 2018). Suicide is the second leading cause of death in children aged 15-29 years.

Depression can affect aspects of life including psychological, physical, and social (Peacock \& Casey, 2000; Mallot, 2014; WHO, 2018). Psychologically depression causes a person to experience constant sadness, loss of hope, low self-esteem, irritability, difficulty making decisions, anxiety, diminished concentration, hesitation, feelings of worthlessness, guilt or despair, loss of interest in doing and running activity as usual, thoughts of self-harm or suicide (Moragne, 2011; Coleman, 2012; Schwartz \& Petersen, 2016; WHO, 2018).

In addition, physically people with depression also experience changes in appetite or weight, constipation, moves or speaks more slowly than usual, unexplained pain, lack of energy or lack of interest in sex (loss of libido), menstrual cycle changes, disorders sleeping (difficulty sleeping at night or getting up early) (Lam, 2012; Hammen \& Watkins, 2013; Schwartz \& Petersen, 2016).

Social aspects, depression causes one to avoid meeting or interacting with others, involvement in fewer social activities, neglecting hobbies and interests, experiencing difficulty in family life at home, poor performance and not working well in the workplace (Peacock \& Casey, 2000; Mallot, 2014; Lam, 2012; Hammen \& Watkins, 2013; Schwartz \& Petersen, 2016).
Depression as a result of the complex interactions of psychological, physical, and social factors causes a person to experience pressure and dysfunction and worsen the life situation of the depressed and depressed person (Peacock \& Casey, 2000; Mallot, 2014; Schwartz \& Petersen, 2016; WHO, 2018). If a person's response to stress is long-lasting and with moderate or severe intensity depression can be a serious health problem and if it continues to affect one's function at work, school and family (Peacock, 2000; Mallot, 2014; WHO, 2018).

There is a link between depression and physical health, eg HIV / AIDS disease (Baijesh, 2015; Mushtaq \& Javed, 2017). This condition has immunosuppressive effects and may accelerate the progression of HIV infection as shown in psychoneuroimmunology studies (Irwin, 2008; Leserman, 2008). One of the efforts of the World Health Organization (WHO) to maintain the mental health of individuals and communities through the promotion of mental health, the prevention of mental disorders, the protection of human rights and the care of people affected by mental disorders (WHO, 2017).

Furthermore, WHO proclaimed October 10 as the world's mental health day with the theme "Depression: Let's Talk." (WHO, 2018). As for prevention programs have been shown to reduce depression through psychological and psychological protection and support, the community approach includes schoolbased programs to improve positive thinking patterns in children and adolescents (WHO, 2018).

Furthermore, some treatments are effective in treating mild to moderate levels of depression such as speech therapy, cognitive behavioral therapy/ psychotherapy while moderate to severe depression levels are given antidepressants (Schwartz \& Petersen, 2016).

Some of the barriers encountered ineffective care include resource shortfalls, lack of trained health care providers, social stigma related to mental disorders, and inaccurate assessment/diagnosis (WHO, 2018). In countries of all income levels, depressed people are often undiagnosed, and others who are not depressed are often misdiagnosed and given antidepressants (WHO, 2018). The World Health Organization (WHO) primary care study found that $60 \%$ of patients treated with antidepressants still develop depression after 
one year of treatment. Individuals with a history of recurrent depression have a high risk of recurrent depression recurrence.

Antidepressant maintenance therapy at least 2 years of treatment is recommended today, but many individuals are interested in alternative medicine (Kuyken, et al., 2015). Although there have been effective treatment therapies to reduce depression there appears to be a need for encouraging innovative and effective treatments. Recent studies offer treatment of psychological interventions such as cognitive behavior therapy (CBT) and MindfulnessBased Cognitive Therapy (MBCT). CBT and MBCT are a type of cognitive therapy (psychotherapeutic intervention) (Tovote, et al., 2017).

Mindfulness-based cognitive therapy (MBCT) is an eight week, group-based, mind-centered group-based intervention that integrates awareness meditation with cognitive behavior therapy (CBT) specifically developed as major depressive disorder prevention (MDD) prevention intervention (Segal et al., 2012).

The MBCT approach is unique because it focuses on developing effective methods that connect with depressive thoughts and feelings rather than challenging or changing specific cognitions as taught in CBT. MBCT teaches patients to deal with unpleasant thoughts, feelings, and body sensations as a temporary accidental occurrence in the mind, rather than identifying or treating it as a reflection of an accurate reality. Several studies have investigated MBCT as an augmentative treatment for acute depression (Kuyken, et al., 2015).

Although MBCT is still something new, there is empirical evidence supporting the effectiveness of MBCT in reducing depression and improving the quality of life and health of people suffering from chronic diseases (Tovote, et al., 2017; MacKenzie, et al.,2018).

The purpose of this literature study is to review the publication of the peer review and gray literature health literature in providing information about the effectiveness of Mindfulness-Based Cognitive Therapy (MBCT) towards depression.

\section{METHODS}

\section{Search Strategy}

Relevant literature searches were conducted through several databases including PubMed, ProQuest, DOAJ, Emerald Insight, EBSCO, and Garuda using keywords: mindfulness-based cognitive therapy, depression, and randomized controlled trial. Gray Literature is also searched through relevant sites. Searches performed with the last 5 years publication criteria (2013 through 2017). Search term strategies are performed for example on one of PubMed's electronic database searches: 'mindfulness-based cognitive therapy' and 'depression' and 'randomized controlled trial'.

\section{Inclusion and Exclusion Criteria}

This review aims to provide an overview of the effectiveness of mindfulness-based cognitive therapy on depression levels in a comprehensive and thorough review conducted using a systematic approach including gray literature. The search period from 2013 to 2017. The boundaries of the search for articles in English and each article have been read and identified in full and assessed their relevance for review with inclusion criteria include (1) randomized controlled trial design; (2) research using valid and reliable measuring instrument; (3) participants with diagnostic criteria based on DSM-IV depressive disorder. ICD-10 depressive episodes or depressive disorder. Exclusion criteria include: (1) not evaluating changes in depression levels; (2) articles published in the form of letters, comments, editorials, and do not use English.

\section{Study Selection}

The following information is derived from research that meets the eligibility criteria, among others: first author's name, publication year, research design, demographics and diagnosis of participants, instruments used to measure results and evaluate results.

\section{RESULT}

After an electronic search on the database and identified a total of 633 articles related to mindfulnessbased cognitive therapy (MBCT). Furthermore, checking for duplicate and issued articles, 620 studies consistent with terms / criteria, and full text totaling 
128 articles, 118 did not meet inclusion criteria by reason of not investigating MBCT $(n=61)$, participants were not depressed/depressive disorder ( $n=39$ ), rather than the randomized controlled trial design ( $n=14$ ) of articles published in the form of letters, comments, editorials $(n=4)$. After issuing duplicate articles, the authors independently screen from each article title and abstract from a manuscript that fits the criteria or qualifies. Then, the full text of the manuscripts included in the review amounted to 11 articles. An explanation of the search strategy can be seen in Figure 1.

Figure 1. Flow chart showing search results and article retrieval. RCT = randomized controlled trial

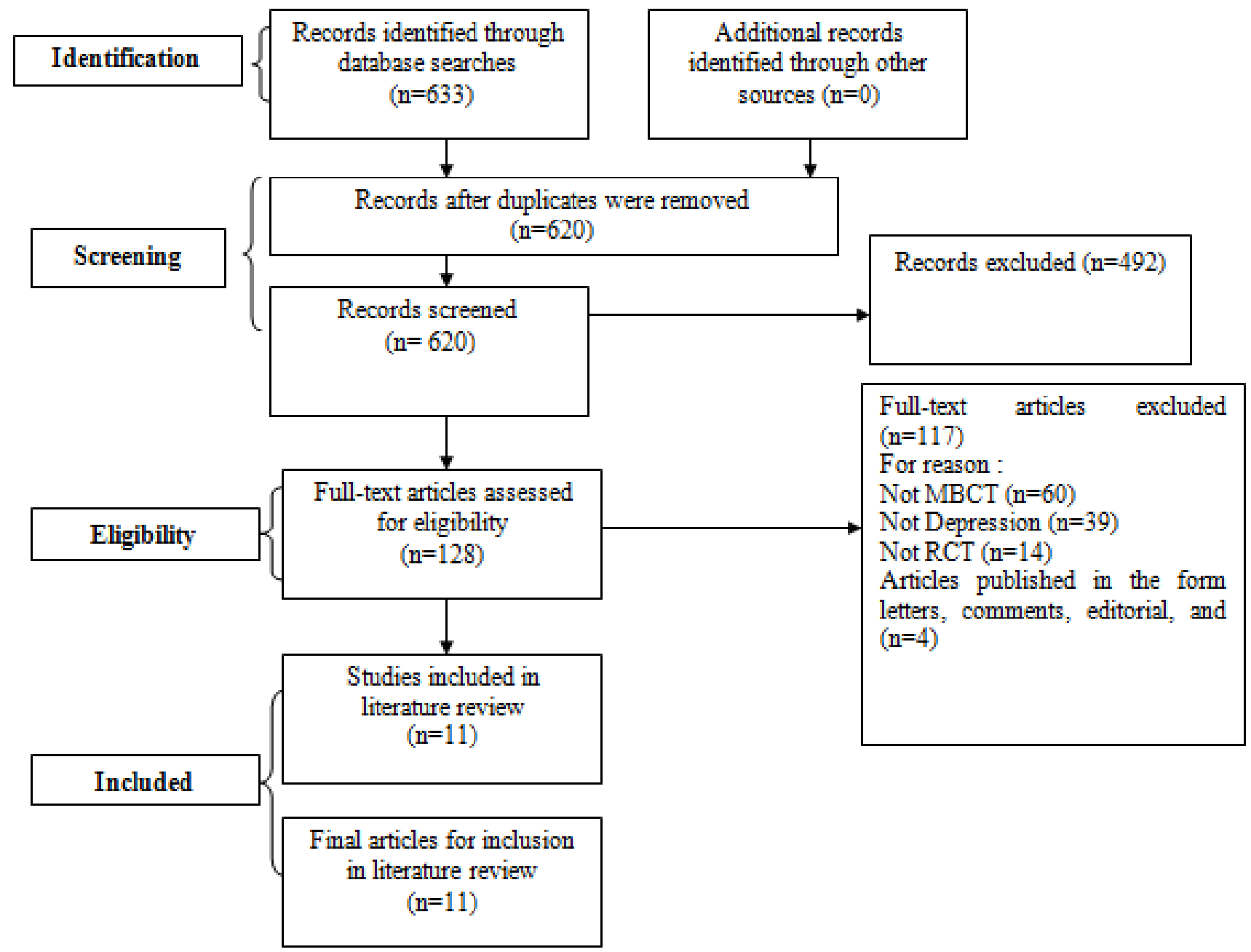

\section{Characteristics of the Study}

Characteristics of the studies included in the review literature are described in table 1. Participants involved in literature studies are depressed patients with health problems of premenstrual syndrome, diabetes, history of depression, depressive symptoms, recurrent depression, mild to severe depression, treatment of depression, depression prevention. The type of intervention was mindfulness-based cognitive therapy (MBCT) in the intervention group while the type of intervention in the control group was Treatment as Usual (TAU), cognitive behavior therapy (CBT), normal care, wait list, cognitive psychoeducation (CPE), health enhancement program (HEP), and active control condition (ACC). The total number of participants in the study was 1609 people. The number of participants for mindfulness-based cognitive therapy (MBCT) intervention $(n=717)$, while in the control group the number of participants was 832 people. Participant age is generally 20-56 years old. This study involved women as many as 1162 people and men as many as 447 people. The duration of intervention given was dominant for 8 weeks while the duration of follow-up time ranged from 3 months to 24 months. 
Table 1. Summary of Key Characteristics of Studies Included in review

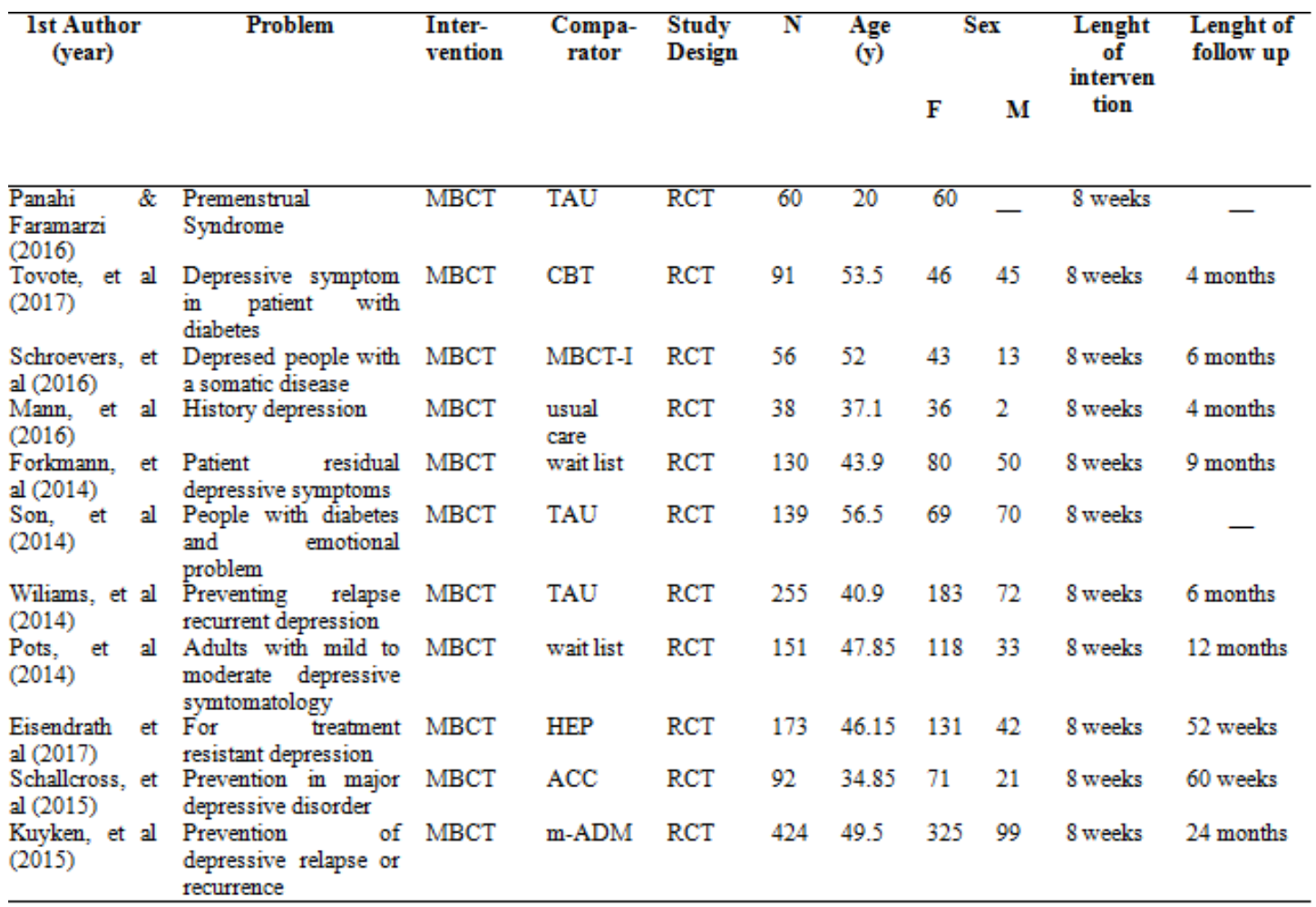

MBCT = mindfulness-based cognitive therapy $;$ MBCT-I = mindfulness-based cognitive therapy individual $;$ TAU = Treatment as Usual, CBT = cognitive behavior therapy ; HEP = health enhancement program; ACC = active control condition ; $\mathrm{m}-\mathrm{ADM}=$ maintenance antidepressant medication

\section{Measurement results}

Table 2 describes the depression score before and after the intervention and the type of instrument used in the assessment.

Table.2 Summary of Depression Outcome Before and After Mindfulness-based cognitive therapy

\begin{tabular}{|c|c|c|c|c|c|c|c|}
\hline $\begin{array}{c}1^{\text {st }} \text { Author } \\
(y)\end{array}$ & Instrument & Group & $\begin{array}{l}\text { Time } \\
\text { point }\end{array}$ & Number & Before & After & Change \\
\hline $\begin{array}{l}\text { Panahi \& } \\
\text { Faramarzi } \\
\text { (2016) }\end{array}$ & $\begin{array}{l}\text { BDI-II } 21 \\
\text { Item }\end{array}$ & $\begin{array}{l}\text { MBCT } \\
\text { TAU }\end{array}$ & 8 weeks & $\begin{array}{l}30 \\
30\end{array}$ & $\begin{array}{l}24.70 \\
24.96\end{array}$ & $\begin{array}{l}15.73 \\
25.36\end{array}$ & 0.007 \\
\hline $\begin{array}{l}\text { Tovote, et al } \\
\text { (2017) }\end{array}$ & $\begin{array}{l}\text { BDI-II } 21 \\
\text { Item }\end{array}$ & $\begin{array}{l}\text { MBCT } \\
\text { CBT }\end{array}$ & 8 weeks & $\begin{array}{l}46 \\
45\end{array}$ & $\begin{array}{l}21.0 \\
23.5\end{array}$ & $\begin{array}{l}12.4 \\
21.7\end{array}$ & 0.012 \\
\hline $\begin{array}{l}\text { Schroevers, } \\
\text { et al (2016) }\end{array}$ & $\begin{array}{l}\text { BDI-II } 21 \\
\text { Item }\end{array}$ & $\begin{array}{l}\text { MBCT-G } \\
\text { MBCT-I }\end{array}$ & 8 weeks & $\begin{array}{l}28 \\
28\end{array}$ & $\begin{array}{l}24.0 \\
25.0\end{array}$ & $\begin{array}{l}10.8 \\
13.1\end{array}$ & $\begin{array}{l}13.3(10.2,16.4) \\
11.6(8.2,15.5)\end{array}$ \\
\hline $\begin{array}{l}\text { Mann, et al } \\
(2016)\end{array}$ & $\begin{array}{l}\text { BDI-II } 21 \\
\text { Item }\end{array}$ & $\begin{array}{l}\text { MBCT-P } \\
\text { Usual care }\end{array}$ & 8 weeks & $\begin{array}{l}19 \\
19\end{array}$ & $\begin{array}{l}13.0 \\
9.51\end{array}$ & - & - \\
\hline $\begin{array}{l}\text { Forkmann, } \\
\text { et al (2014) }\end{array}$ & $\begin{array}{l}\text { HDRS } 17 \\
\text { Item }\end{array}$ & $\begin{array}{l}\text { MBCT } \\
\text { Wait list }\end{array}$ & 8 weeks & $\begin{array}{l}64 \\
66 \\
\end{array}$ & $\begin{array}{l}10.27 \\
10.21\end{array}$ & $\begin{array}{l}7.14 \\
9.68\end{array}$ & 0.00 \\
\hline $\begin{array}{l}\text { Son, et al } \\
\text { (2014) }\end{array}$ & HADS & $\begin{array}{l}\text { MBCT } \\
\text { TAU }\end{array}$ & 8 weeks & $\begin{array}{l}70 \\
69\end{array}$ & $\begin{array}{l}8.2 \\
9.2\end{array}$ & $\begin{array}{l}5.6 \\
8.6 \\
\end{array}$ & 0.004 \\
\hline $\begin{array}{l}\text { Wiliams, et } \\
\text { al (2014) }\end{array}$ & HAMD & $\begin{array}{l}\text { MBCT } \\
\text { CPE } \\
\text { TAU }\end{array}$ & 8 weeks & $\begin{array}{l}99 \\
103 \\
53\end{array}$ & $\begin{array}{l}3.17 \\
3.55 \\
2.57\end{array}$ & - & - \\
\hline $\begin{array}{l}\text { Pots, et al } \\
\text { (2014) }\end{array}$ & HADS & $\begin{array}{l}\text { MBCT } \\
\text { WAIT } \\
\text { LIST }\end{array}$ & 8 weeks & $\begin{array}{l}76 \\
75\end{array}$ & $\begin{array}{l}7.96 \\
8.57\end{array}$ & $\begin{array}{l}6.14 \\
8.22\end{array}$ & 0.001 \\
\hline $\begin{array}{l}\text { Eisendrath, } \\
\text { et al (2017) }\end{array}$ & HAM-D17 & $\begin{array}{l}\text { MBCT } \\
\text { HEP }\end{array}$ & 8 weeks & $\begin{array}{l}87 \\
86 \\
\end{array}$ & $\begin{array}{l}24 \\
23 \\
\end{array}$ & $\begin{array}{l}25.3 \\
36.6 \\
\end{array}$ & $<0.05$ \\
\hline $\begin{array}{l}\text { Schallross, } \\
\text { et al (2015) }\end{array}$ & BDI-II & $\begin{array}{l}\text { MBCT } \\
\text { ACC }\end{array}$ & 8 weeks & $\begin{array}{l}46 \\
46 \\
\end{array}$ & $\begin{array}{l}12.1 \\
11.9 \\
\end{array}$ & $\begin{array}{l}11.9 \\
7.1\end{array}$ & $<0.01$ \\
\hline $\begin{array}{l}\text { Kuyken, et } \\
\text { al (2015) }\end{array}$ & BDI-II & $\begin{array}{l}\text { MBCT } \\
\text { m-ADM }\end{array}$ & 8 weeks & $\begin{array}{l}212 \\
212 \\
\end{array}$ & $\begin{array}{l}13.8 \\
14.4\end{array}$ & $\begin{array}{l}11.6 \\
11.9\end{array}$ & 0.21 \\
\hline
\end{tabular}




\section{DISCUSSION}

This literature review traces the effectiveness of mindfulness-based cognitive therapy (MBCT) against depression levels. Based on literature search results, there were 11 RCT studies (1609 participants) that met the inclusion criteria. Participants are people who are depressed from mild to moderate levels. Besides, most participants were women as many as 1162 (72.2\%) people with an average age of $20-56$ years. The study results elucidate other contexts of depression in the population associated with other diseases such as premenstrual syndrome, somatic disease, diabetes, prevention of depression, and treatment of resistant depression.

The review literature review explains that mindfulness-based cognitive therapy (MBCT) is effective in reducing depression with 8 weeks of treatment or treatment effect. This is supported by Panahi \& Faramarzi (2016) research that found that mindfulness-based cognitive therapy (MBCT) as a psychotherapy and treatment option significantly reduces depression in women with premenstrual syndrome (PMS).

Panahi \& Faramarzi also added that MBCT is an acceptable intervention by women with PMS symptoms, has a potentially beneficial effect in reducing the symptoms of depression from mild to moderate levels in women with premenstrual syndrome. Furthermore, MBCT is effective as an acceptable, potentially, accessible, feasible and workable mental health intervention (Tovote, et al, 2017; Mann, et al, 2016; Pots, et al, 2014; Eisendrath, et al, 2017 ).

In another study review, Schroevers, et al (2016) also found that mindfulness-based cognitive therapy (MBCT) significantly reduced depression in patients with the somatic disease. A Somatic disease is a disorder that causes a person to experience many physical symptoms without a known cause and can disrupt a person for months or years and cause tremendous suffering. This can be triggered by medical uncertainty resulting in persistent worries and psychological distress. Somatic symptoms of persistent physical health complaints that may or may not be related to medical or psychological conditions such as abdominal pain are associated with irritable bowel syndrome, cardiac palpitations associated with panic disorder (McHugh \& Vallis, 2012; Jovanovic, 2017; Wiliams \& Zahka, 2017).
Furthermore, Scroevers, et al (2016) subdivided MBCT into MBCT group and individual MBCT. The results show that both the MBCT group and individual MBCT both show improved psychological well-being, skill, self-confidence in individuals with chronic somatic conditions and symptoms of comorbid depression. This is in line with Mann's research, et al (2016) indicating that MBCT may reduce depressive symptoms in parents with a history of depression.

Based on Forkmann et al (2014) in his study investigating the effectiveness of MBCT against the idea of suicide with patients with residual depressive symptoms the results also showed that there was a significant reduction in the idea of suicide in the MBCT group and this effect was mediated by the increased ability of participants to distance themselves from worrying thoughts. Further, on Son's findings, et al (2014) showed that there was a significant effect of MBCT on stress from follow-up for 6 months.

Also, mindfulness-based cognitive therapy (MBCT) has sustained effectiveness in reducing emotional stress for diabetic patients, improving social welfare. Son, et al (2014) also suggested that MBCT could serve as an important additional strategy in the treatment of diabetes because of the emerging emotional stress associated with poor diabetes outcomes.

Pots, et al (2014) also reported that MBCT may decrease depression, anxiety, and improvement in mental and emotional awareness and mental health. Pots, et al describes MBCT as a community mental health intervention for adults with mild to moderate depressive symptoms. Further on Eisendrath's findings, et al (2017) demonstrated that MBCT can reduce the severity of depression, improve treatment response at 8 weeks but not at remission levels, and as appropriate interventions in the management of depression-resistant treatment.

Only 3 of the 11 studies in this review did not show significant results. Differences found by Wiliams, et al (2014) suggest that MBCT can provide significant protection against recurrence for participants with increased susceptibility due to childhood trauma history but does not show significant gains in the overall group of patients with recurrent depression and lack of the risk of relapse to major depressive disorder (MDD) during the 12-month follow-up period, but the severity of childhood trauma affected by the recurrence. 
Schallcross, et al (2015) in his study comparing MBCT and active control conditions (ACC). The results showed that there was no significant difference in reducing the relapse rate and symptoms of depression. However, both MBCT and ACC can reduce symptoms of depression and improve quality of life and are significantly equivalent. Similar findings in the Kuyken, et al (2015) study comparing MBCT and maintenance of antidepressant medication (m-ADM) results show that MBCT is not superior to $m-A D M$ for the prevention of depression relapse. Both are associated with persistent positive outcomes in relapse, residual depressive symptoms, and quality of life.

Dominant in 11 studies, the duration required for mindfulness-based cognitive therapy (MBCT) interventions was 8 weeks. While the time required in follow up is more effective $\leq 12$ weeks. As expressed by Tovote, et al (2017) the MBCT effect was not observed at 9 months follow-up. Son, et al (2014) explained that there was no significant difference up to 6 months

\section{BIBLIOGRAPHY}

Baijesh, A. (2015). Mindfulness Based Cognitive Therapy for Depression among HIV-Infected Individuals. International Journal of Indian Psychology, 3, 2349-3429.

Coleman, L. H. (2012). Depression: A Guide for the Newly Diagnosed. Canada: Raincoast Books.

Eisendrath, S. ., Gillung, E., Delucchi, K. ., Segal, Z. ., Nelson, J. ., McInnes, L. ., \& Feldman, M. . (2016). A Randomized Controlled Trial of MindfulnessBased Cognitive Therapy for TreatmentResistant Depression, 85(2), 99-110. https:// doi.org/10.1159/000442260

Forkmann, T., Wichers, M., Geschwind, N., Peeters, F., Os, J. van, Mainz, V., \& Collip, D. (2014). Effects of mindfulness-based cognitive therapy on self-reported suicidal ideation: results from a randomised controlled trial in patients with residual depressive symptoms, 55(8), 18831890. https://doi.org/10.1016/j.comppsych. 2014.08.043

Hammen, C. L., \& Watkins, E. (2013). Depression Clinical Psychology: A Modular Course. USA: Psychology Press. follow up. Pots, et al (2014) showed that symptoms of depression were clinically significantly higher for the MBCT group at 3 months of follow-up. Schallcross, et al (2015) described no significant difference in reducing the rate of depression relapse and relapse time during 60 weeks of follow-up.

\section{CONCLUSION}

Mindfulness-based cognitive therapy (MBCT) is an effective, acceptable, feasible, accessible, and applicable form of mental health psychotherapeutic intervention for both individuals and groups, men and women with an average age of 20-56 years who aim to reduce symptoms depression, anxiety, emotional stress as well as improving quality of life, improving social welfare, and improving psychological well-being either because of depression itself or by other causes of comorbid diseases such as premenstrual syndrome, diabetes, somatic disease, and a history of depression with a duration of 8 weeks follow up $\leq 12$ weeks.

Irwin, M. . (2008). Human psychoneuroimmunology: 20 Years of discovery. Brain, Behavior, and Immunity, 22(2), 129-139. https://doi. org/10.1016/j.bbi.2007.07.013

Kuyken, W., Hayes, R., Barrett, B., Byng, R., Dalgleish, T., Kessler, D., ... Byford, S. (2015). Effectiveness and cost-effectiveness of mindfulness-based cognitive therapy compared with maintenance antidepressant treatment in the prevention of depressive relapse or recurrence (PREVENT): a randomised controlled trial, 4;386(9988), 6373. https://doi.org/10.1016/S0140-6736(14) 62222-4. Epub 2015 Apr 20

Lam, W. R. (2012). Depression. Canada: OUP Oxford.

Leserman, J. (2008). Role of Depression, Stress, and Trauma in HIV Disease Progression. Psychosomatic Medicine, 70(5), 539-545. https://doi.org/10.1097/psy.0b013e31817 $77 \mathrm{a} 5 \mathrm{f}$

MacKenzie, M., Abbott, K., \& Kocovski, N. (2018). Mindfulness-based cognitive therapy in patients with depression: current perspectives. Neuropsychiatric Disease and Treatment, 14, 1599-1605. https://doi.org/10.2147/ndt.s16 0761 
Mallot, P. (2014). Depression : Practical Guide to SelfHelp. USA: New Harbinger.

Mann, J., Kuyken, W., O’Mahen, H., Ukoumunne, O. ., Evans, A., \& Ford, T. (2016). Manual Development and Pilot Randomised Controlled Trial of Mindfulness-Based Cognitive Therapy Versus Usual Care for Parents with a History of Depression, 7(5), 1024-1033. https://doi. org/10.1007/s12671-016-0543-7

Moragne, W. (2011). Depression. USA: Twenty-First Century Books.

Murray, C. J. ., \& Lopes, A. . (1996). Evidence-Based Health Policy---Lessons from the Global Burden of Disease Study. Science, 274(5288), 740-743. https://doi.org/10.1126/science.274.5288.740

Mushtaq, S., Gaur, R. K., \& Javed, S. (2017). Effectiveness of Mindfulness Based Cognitive Therapy on Quality of Life, Life Satisfaction and Depression of Patients with HIV/AIDS, 6(6). Retrieved from https://wwjournals.com/index.php/ijsr/ article/view/11900/11821

Panahi, F., \& Faramarzi, M. (2016). The Effects of Mindfulness-Based Cognitive Therapy on Depression and Anxiety in Women with Premenstrual Syndrome. Depression Research and Treatment, 1-7. https://doi. org/10.1155/2016/9816481

Peacock, J., \& Casey, J. (2000). Depression Perspectives on Mental Health Series. USA: Capstone Press.

Pots, W. T. ., Meulenbeek, P. A. ., Veehof, M. ., Klungers, J., \& Bohlmeijer, E. . (2014). The Efficacy of Mindfulness-Based Cognitive Therapy as a Public Mental Health Intervention for Adults with Mild to Moderate Depressive Symptomatology: A Randomized Controlled Trial. PLoS ONE, 9(10), e109789. https://doi.org/10.1371/journal.pone. 0109789

Schallross, A. ., Gross, J. ., Visvanathan, P. ., Kumar, N., Palfrey, A., Ford, B. ., \& Mauss, I. . (2015). Relapse prevention in major depressive disorder: Mindfulness-based cognitive therapy versus an active control condition. Journal of Consulting and Clinical Psychology, 83(5), 964-975. https://doi.org/10.1037/ccp0000050
Schroevers, M. ., Tovote, K. ., Snippe, E., \& Fleer, J. (2016). Group and Individual MindfulnessBased Cognitive Therapy (MBCT) Are Both Effective: a Pilot Randomized Controlled Trial in Depressed People with a Somatic Disease. Springer US, 7(1339). https://doi.org/10.1007/ s12671-016-0575-z

Schwartz, T. L., \& Petersen, T. (2016). Depression: Treatment Strategies and Management 'Medical Psychiatry Series. New York: CRC Press.

Segal, Z. V., Williams, J. M. ., \& Teasdale, J. D. (2012). Mindfulness-Based Cognitive Therapy For Depression ( $2^{\text {nd }}$ ed.). USA: Guildford Press.

Tovote, K. ., Schroevers, M. ., Snippe, E., Emmelkamp, P. M. ., Links, T. ., Sanderman, R., \& Fleer, J. (2017). What works best for whom? Cognitive Behavior Therapy and Mindfulness-Based Cognitive Therapy for depressive symptoms in patients with diabetes. PLoS ONE, 12(6), e0179941. https://doi.org/10.1371/journal. pone.0179941

Van Son, J., Nyklíček, I., Pop, V. ., Blonk, M. ., Erdtsieck, R. ., \& Pouwer, F. (2014). Mindfulness-based cognitive therapy for people with diabetes and emotional problems: Long-term followup findings from the DiaMind randomized controlled trial. Journal of Psychosomatic Research, 77(1), 81-84. https://doi. org/10.1016/j.jpsychores.2014.03.013

WH0.2018. Depression. Date of access : 09/12/2018. https://www.who.int/news-room/fact-sheets/ detail/depression

WHO.2001.The world health report 2001 - Mental Health: New Understanding, New Hope. https:// www.who.int/whr/2001/en/

Williams, J. M. ., Crane, C., Barnhofer, T., Brennan, K., Duggan, D. ., Fennel, M. J. ., \& Russell, I. . (2014). Mindfulness-based cognitive therapy for preventing relapse in recurrent depression: A randomized dismantling trial. Journal of Consulting and Clinical Psychology, 82(2), 275-286. https://doi.org/10.1037/ a0035036 